\title{
The effect of training on workers' perceived job match quality
}

\author{
Yi Zhang ${ }^{1,2} \cdot$ Martin Salm ${ }^{2} \cdot$ Arthur van Soest ${ }^{2,3}$
}

Received: 24 August 2018 / Accepted: 7 February 2020 / Published online: 2 March 2020

(c) The Author(s) 2020

\begin{abstract}
We study the causal effect of training on job match quality using longitudinal data for a representative sample of the Dutch population. We construct an index of workers' perceived job match quality from five survey questions on job satisfaction and on how a worker's education and skills match with the job. Based on a dynamic linear panel data model, which accounts for potential endogeneity in training, we find that training has significantly positive short- and long-term effects on job match quality. This is mainly driven by training for human capital accumulation. Further analysis incorporating job changes shows that training for job change purpose increases the probability to change jobs, but job changes immediately following this type of training do not significantly increase job match quality. On the other hand, those who change jobs 1 year after this training do tend to get a better-matched job.
\end{abstract}

Keywords Training $\cdot$ Job match quality $\cdot$ Human capital $\cdot$ Job changes

JEL Classification C23 $\cdot$ J24 $\cdot$ J28 $\cdot$ M53

\section{Introduction}

Job match quality is increasingly recognized as an important predictor not only of individuals' psychological, social, and economic well-being, but also of firm pro-

Electronic supplementary material The online version of this article (https://doi.org/10.1007/s00181020-01833-3) contains supplementary material, which is available to authorized users.

$凶$ Yi Zhang

y.zhang_3@hotmail.com

1 China Center for Human Capital and Labor Market Research, Central University of Finance and Economics, 39 South College Road, Haidian District, Beijing, P.R. China

2 Department of Econometrics and Operations Research, Tilburg University, PO Box 90153, 5000

LE Tilburg, The Netherlands

3 Netspar, Tilburg University, PO Box 90153, 5000 LE Tilburg, The Netherlands 
ductivity, and even of economic growth. Individual-level analyses have shown that low job match quality, or mismatch, is closely associated with wage penalties, absenteeism, high turnover, and other negative labor market outcomes, even controlling for wages, working hours, and standard demographic and job characteristics (Vahey 2000; Dolton and Vignoles 2000; Allen and van der Velden 2001; Clark 2001; Green and Zhu 2010; Nordin et al. 2010; Mavromaras et al. 2013; Pecoraro 2014; Congregado et al. 2016). Firm-level meta-analysis finds that higher job match quality is related to higher employee engagement and firm profitability and productivity (Harter et al. 2002).

Moreover, "improving job match quality" is a strategic goal of the European Union: the 10-year strategy of Europe 2020 identifies "better matching labor supply and demand" and "developing skills throughout the lifecycle" as new engines to boost economic growth and to increase job quality. ${ }^{1}$ The recent Strategic Framework for Health and Safety at Work 2014-2020 emphasizes the importance of improving job quality for the competitiveness and productivity of European companies. ${ }^{2}$

In spite of the acknowledged importance of job match quality, there is limited empirical research on how job match quality can be improved. A possible measure to improve job match quality that has been frequently discussed is training. However, studies that aim to estimate the effect of training on job match quality face two challenges. First, there is no unanimous definition of job match quality, and second, it is difficult to identify a causal effect of training on job match quality.

The quality of a job match indicates how well the characteristics of a worker match those of a job. Job match quality can be defined either from the worker's perspective (Kalleberg and Vaisey 2005; Clark 2015), or from the firm's perspective (Jones et al. 2009), using objective measures (Gaure et al. 2012; Lachowska et al. 2016; Le Barbanchon 2016) or subjective measures (Gottschalk and Maloney 1985; Clark 2005; Ferreira and Taylor 2011).

In this study, we use a measure of workers' perceived job match quality that captures the multidimensional quality of a job match. Following the example of Ferreira and Taylor (2011), we use factor analysis to derive a continuous measure of job match quality from five job match-related questions. Our measure is a combination of educational match, skill match, and satisfaction with the job. The use of job satisfaction as a measure of job match quality goes back to Ferreira and Taylor (2011) and Barmby et al. (2012). Our measure is correlated with observed job characteristics and educational background, and it predicts on-the-job search even after controlling for observed job characteristics, education, and individual fixed effects.

We use a broad concept of training - any course or educational program important for work or profession. This includes training on the job as well as off the job. Our aim is to estimate the causal effect of training on job match quality. Training can affect job match quality in multiple ways. First, training can increase human capital and individual productivity, as implied by human capital theory (Becker 1962). This

\footnotetext{
1 http://eur-lex.europa.eu/LexUriServ/LexUriServ.do?uri=COM:2010:2020:FIN:EN:PDF.

2 http://eur-lex.europa.eu/legal-content/EN/TXT/PDF/?uri=CELEX:52014DC0332. Strictly speaking, job quality is not the same as job match quality. Job quality focuses on job characteristics, and it is a part of job match quality.
} 
could improve the perceived job match quality through a wage increase. Even without a wage increase, training could still improve the perceived match quality by filling gaps in knowledge and skills and by making employees feel more competent at their jobs. Second, training may have an indirect impact on match quality through job changes. Training can influence the probability of matching to a new job with higher requirements and usually also with higher wages, as implied by the theory of career mobility (Sicherman and Galor 1990), ${ }^{3}$ which could lead to a change in the perceived match quality after switching to a new job. ${ }^{4}$

We estimate a dynamic linear panel data model, using 8 years of data from the Dutch LISS data (Longitudinal Internet Studies for the Social sciences). A challenge for estimating the causal effect of training on job match quality is that training can be endogenous to job match quality. One reason is the presence of time persistent unobserved factors that drive participation in training and job match quality in related ways. For example, more ambitious people may select themselves into training and may also be more likely to find a better-matched job. In our panel data models, we account for this using fixed individual effects, allowed to be correlated with training and other regressors. Second, training can be directly affected by job match quality if, for example, training aims at making up for the lack of skills required for the current job (i.e., the imperfect nature of the job match) or if training is taken because employees are dissatisfied with their job and wish to improve their labor market opportunities. We address the potential endogeneity of training exploiting the timing of events, assuming that shocks in job match quality are not correlated with past training (or other events in the past). This implies that we can use lagged variables of training as instruments for current training and apply GMM.

We find positive effects of training on job match quality both in the short-run and long-run. This finding is robust to alternative definitions of job match quality and training. We then explore possible pathways. First, since training for different purposes has different content and possibly different effects on job match quality, we estimate a model that allows for heterogeneous effects of training. Our results indicate that the effect of training is largest for training aimed at human capital improvement, in accordance with human capital theory. We also find some evidence supporting the theory of career mobility: we find that training for the purpose of a job change immediately increases the probability to change jobs. However, these new jobs are as often better matches as worse matches. On the other hand, for those who do not change jobs immediately but in the next period, training for job change purposes significantly improves job match quality. Finally, we find no evidence that training for

\footnotetext{
3 Note that human capital theory and career mobility theory are not mutually exclusive. The key distinction is that the original human capital theory only considers wage as the return of human capital investment, while care mobility theory provides additional dimensions of return, i.e., inter- or intra-firms occupational upgrading.

${ }^{4}$ Similar mechanisms of how training can influence job match quality can also be derived from a search and matching framework (see, e.g., Mortensen 1978; Jovanovic 1979; Topel and Ward 1992). On the one hand, match quality is revealed to both workers and firms as time elapses. If training affects productivity through human capital build-up, then it would affect the perceived quality of the work-firm match. On the other hand, training could increase the search ability of the worker (e.g., training on CV writing skills leads to higher success rate of matching with any new job), or increase the probability of matching to jobs with higher quality (e.g., certificates allow workers to send signals to more challenging and better paid jobs).
} 
other purposes (mainly training referred to as "required for my job") has any effects on either job match quality or the likelihood to switch jobs.

Our study makes two contributions to the literature. First, we provide evidence for a causal effect of training on job match quality based on a dynamic panel data model. Existing empirical studies either focus on the association between training and match quality (Chiang et al. 2005; Jones et al. 2009; Han et al. 2014), ${ }^{5}$ or they identify a causal effect using different identifying assumptions than we use. For example, some previous studies assume that training is exogenous after conditioning on a set of observed characteristics (Georgellis and Lange 2007; Messinis and Olekalns 2008; Burgard and Görlitz 2014; Pagán-Rodríguez 2015). In contrast, our study addresses the endogeneity of training exploiting the timing of events based on a dynamic panel data model.

Furthermore, we examine the mechanisms underlying the effect of training on match quality. For this purpose, we provide evidence for a causal effect of training on job changes and on job match quality after a job change. A previous study by Dekker et al. (2002) examines how training influences upward and lateral job mobility. However, limited by the cross-sectional nature of their data, they are not able to address the potential endogeneity in training. In contrast, this endogeneity can be accounted for with our empirical strategy.

Our paper continues as follows: Sect. 2 describes the data and the measurement of main variables. Section 3 presents the main empirical analysis for the effect of training on job match quality. Section 4 presents a more detailed analysis aimed at identifying mechanisms that explain this effect. Section 5 lists sensitivity analyses. Section 6 concludes.

\section{Data and measurement}

We use data from the LISS panel (Longitudinal Internet Studies for the Social Sciences) administered by CentERdata affiliated with Tilburg University, which provides a representative sample of approximately 5000 Dutch households. ${ }^{6}$ We combine LISS Panel Background Information and the module of Working and Schooling Survey (2008-2015, eight waves). The latter is a longitudinal survey on labor market participation, job characteristics, pensions, schooling and training courses, etc. ${ }^{7}$ The dataset is ideal for our analysis. It provides information about the match between the job and an individual's education and skills, which is rare in other longitudinal household datasets. Furthermore, the panel is long enough to estimate dynamic linear panel data models.

\footnotetext{
5 Studies on job assistance programs sometimes use objective one-dimensional measures, e.g., job duration (Blundell et al. 2004) and wage (Crépon et al. 2013), etc., to indicate the quality of a job match. This is not our focus. The job match quality of our interest is from a subjective and multidimensional perspective.

6 See https://www.lissdata.nl/lissdata/about-panel for detailed information of the LISS Panel.

7 See http://www.lissdata.nl/dataarchive/studyunits/view/1 for more modules of the LISS Panel.
} 
We apply some restrictions to our sample. We only keep individuals doing paid work and drop logically inconsistent observations. ${ }^{8}$ We only keep workers appearing in the dataset for at least two consecutive years, since we need information on at least one lag in the econometric model. ${ }^{9}$ We drop observations with missing values in main explanatory variables, e.g., training and job changes. The remaining sample size is 4905 individuals and 21,992 individual-year observations. The structure of the resulting unbalanced panel is listed in the Online Appendix Table A.1.

\subsection{Perceived job match quality}

From a worker's perspective, a measure of job match quality should be able to capture how "good" the job match is. This is a multidimensional concept, not only determined by contracted job characteristics (e.g., wage, hours of work, etc.) and education background of the worker, but also influenced by match-specific characteristics only perceived by the worker like stressfulness, working atmosphere, self-realization, etc. To capture observed and unobserved aspects of job match quality, there are two ways to construct a measure of workers' perceived job match quality. First, workers could be asked many detailed questions on satisfaction with pay, hours of work, future prospects, work pressure, job content, interpersonal relationships, etc., and all these aspects of the job could be aggregated into a single measure. The practical problem with this method is that researchers can hardly be exhaustive in including all the relevant job aspects. Usually in survey data, questions on satisfaction cover a limited number of job aspects. The alternative is to ask more general questions about how good the job match is, assuming that respondents will aggregate the more detailed observed and unobserved aspects of job match quality themselves.

We choose the second method and use five job match-related questions: (1) one question about educational match: "how does your highest level of education suit the work that you now perform." (2) One question about skill match: "how do your knowledge and skills suit the work you do." (3-5) Three questions about overall satisfaction of the job match: "How satisfied are you with the type of work that you do/your career so far/your current work."10 Table 1 shows some sample statistics for these five variables on a scale from 0 to $9 .{ }^{11}$ For each of the five variables, a higher value points at better job match quality. On average, the educational match (question 1 ) is evaluated substantially worse than the other four aspects of job match quality.

\footnotetext{
8 For example, for the variable "year when entering the current job" (used to construct an indicator for changing jobs) in 2008, an individual reported entering the current job in 2006. But in 2010, she reported entering the current job in 1984. Observations with such logically inconsistent answers are dropped.

9 We start with 12,328 individuals and 48,752 individual-year observations. Keeping individuals doing paid work reduces the sample to 29,016 observations (8748 individuals). By dropping logically inconsistent observations, we are left with 25,850 observations (8092 individuals). Keeping those who appear in the dataset for at least two consecutive years reduces the sample to 22,454 observations (5023 individuals).

10 In sensitivity analysis (Sect. 5), we use a larger set of survey questions to construct an index of job match quality. The main results remain the same.

11 The original variables range from 0 (worst) to 10 (best) in all years except 2011, when they range from 0 to 9. For all years except 2011 we combined the two lowest scores (which are rarely reported) and recoded scores from 0 to 9 , leading to very similar distributions in all years.
} 
Table 1 Five job match-related variables

\begin{tabular}{llllllll}
\hline Variable & \multicolumn{2}{l}{ Overall } & \multicolumn{3}{l}{ In year 2011 } \\
\cline { 2 - 3 } & Obs & Mean & SD & & Obs & Mean & SD \\
\hline Educational match & 21,992 & 5.633 & 2.524 & & 2462 & 5.763 & 2.425 \\
Skill match & 21,992 & 6.407 & 1.865 & & 2462 & 6.485 & 1.798 \\
Satisfaction with type of work & 21,793 & 6.627 & 1.551 & & 2433 & 6.601 & 1.589 \\
Satisfaction with career & 21,732 & 6.292 & 1.528 & & 2434 & 6.277 & 1.555 \\
Satisfaction with current work & 21,800 & 6.448 & 1.511 & & 2438 & 6.42 & 1.53 \\
\hline
\end{tabular}

Table 2 Correlations of job match-related variables

\begin{tabular}{llllll}
\hline & $\begin{array}{l}\text { Educational } \\
\text { match }\end{array}$ & Skill match & $\begin{array}{l}\text { Satisfaction } \\
\text { with types of } \\
\text { work }\end{array}$ & $\begin{array}{l}\text { Satisfaction } \\
\text { with career }\end{array}$ & $\begin{array}{c}\text { Satisfaction } \\
\text { with current } \\
\text { work }\end{array}$ \\
\hline $\begin{array}{c}\text { Educational } \\
\text { match }\end{array}$ & 1.000 & & & \\
$\begin{array}{c}\text { Skill match } \\
\begin{array}{c}\text { Satisfaction of } \\
\text { type of work }\end{array}\end{array}$ & 0.609 & 1.000 & 0.425 & 1.000 & \\
$\begin{array}{c}\text { Satisfaction of } \\
\text { career }\end{array}$ & 0.352 & 0.415 & 0.692 & 1.000 & \\
$\begin{array}{c}\text { Satisfaction of } \\
\text { current work }\end{array}$ & 0.286 & 0.374 & 0.825 & 0.736 \\
\hline
\end{tabular}

Table 2 shows that there are high positive correlations among the answers to the five questions; the high value of Cronbach's alpha of $0.807>0.7$ confirms their high internal consistency, as an indicator of an underlying factor. Following Ferreira and Taylor (2011), we therefore use factor analysis to derive a continuous measure of job match quality from the five job match-related variables. The first latent factor (the linear combination of the five variables that explains the most variation in the pooled data) is a summary measure of the perceived quality of the job match. ${ }^{12}$ Table 3 lists the factor loadings, which indicate the relative importance of each of the five questions. ${ }^{13}$

The constructed index of job match quality gives higher weights to satisfaction with work and career than to the self-reported level of educational and skill match. In sensitivity analysis, we also use a simple average of the five components of job match quality, and the main results are robust to the weighting.

\footnotetext{
12 The factor extraction method is iterated principal factor (IPF); the maximum-likelihood factor method gave very similar results. We only retain the first factor because this is the only one with eigenvalue larger than 1. (The eigenvalues of the five factors are $2.669,0.549,-0.051,-0.121$, and -0.205 .)

13 The highest factor loading in Table 3 is 0.364 . The literature does not reach a consensus on the suggested criteria for factor loadings. For example, Hair et al. (1998) suggest a minimum factor loading of 0.3 for a sample of size 350. Stevens (1992) suggests 0.4 irrespective of the sample size. Child (2006) relaxes it to 0.2 . These criteria are often used for selecting variables for extraction. In our study, we do not use a data-driven approach to select variables. Instead, we select variables based on economic intuition. In our case, the factor loadings show the relative importance of each variable to the latent factor.
} 
Table 3 Factor loadings

Factor loadings

\begin{tabular}{ll}
\hline Educational match & 0.104 \\
Skill match & 0.126 \\
Satisfaction with type of work & 0.364 \\
Satisfaction with career & 0.254 \\
Satisfaction with current work & 0.289
\end{tabular}

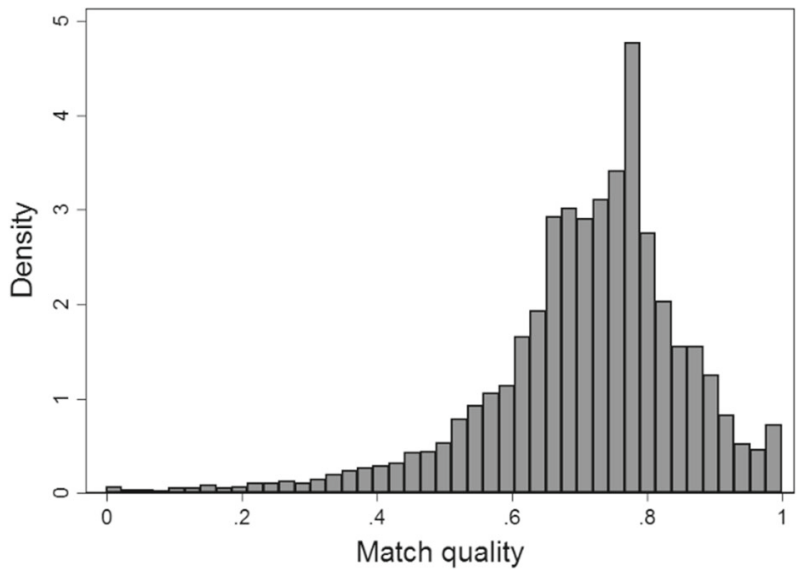

Fig. 1 Distribution of job match quality

With the loadings of the first factor, we predict the dependent variable for each individual and rescale it to obtain our final index of job match quality on a continuous scale from 0 to 1 , with mean 0.711 and standard deviation 0.149 . Figure 1 displays the distribution of the index, which is asymmetric and left-skewed, with a small minority of workers with very low job match quality. In a sensitivity check (Sect. 5), we will analyze the influence of these very low values on our results.

To validate our constructed measure of job match quality, we first investigate how it relates to education and job characteristics (Online Appendix Table A.2, Column 1). Controlling for individual fixed effects, job match quality is influenced by field of study, type of contract, income level, ${ }^{14}$ job sector, supervision level, working hours, tenure, and commuting time. Second, we check whether our index of job match quality is predictive of a worker's on-the-job search behavior (Table A.2, Column 2). Controlling for individual unobserved heterogeneity and all the observed education and job characteristics, we still find that higher job match quality predicts lower incidence of on-the-job search. ${ }^{15}$ This implies that our constructed measure of job match quality

\footnotetext{
${ }^{14}$ Unfortunately, we do not have wage information in the data. Instead, we look at the level of net income. Income level is defined as: 0:"No income"; 1:"EUR 500 or less"; 2:"501-1000"; 3: "1001-1500"; 4: “1501-2000"; 5:"2001-2500"; 6:"2501-3000"; 7:"3001-3500"; 8:"3501-4000"; 9:"4001-4500"; 10:"4501-5000"; 11:"5001-7500"; 12:"More than 7500".

15 The dummy variable for on-the-job search is constructed from the question: "I perform paid work, but am looking for more or other work. (0 no. 1 yes.)".
} 
is able to capture at least part of the unobserved quality of a match from a worker's perspective. Moreover, it confirms that how people feel about job matches actually matters for their labor market behavior.

\subsection{Training}

We use the following question to construct a dummy variable for training in our main estimation:

Have you, in the past 12 months, followed any educational programs or courses or are you presently following one or more educational programs or courses? This concerns educational programs or courses that are important for your work or profession. (1 yes. 2 no.)

The definition of training here is broader than in the previous literature, and it includes both on-the-job training and off-the-job training. Due to the flexible Dutch education system, many people take part in formal education programs while working, e.g., a part-time vocational education program, or a night university program to get certificates for a profession, etc. We allow for a variety of learning activities as long as they are considered as important for work or profession.

The status of receiving training or not is updated each year. There are 8096 individual-year observations taking training. A respondent could take multiple training programs. Respondents taking training were asked to report at most three training programs in the last 12 months. Totally, 3297 and 1091 out of 8096 observations reported to participate in a second and a third training program, respectively. In a sensitivity analysis, we constructed two mutually exclusive dummy variables "receiving a single training program" and "receiving multiple training programs." We find that the effect of "multiple training" is not significantly different from that of "single training." Therefore, we do not use the number of training programs in our analysis. As a measure of training intensity, we also constructed "total days of training per year." It is the sum of the days spent in all three training programs (if applicable) per individual-year. ${ }^{16}$ Conditional on participating in training, the average total days of training per individual and year is 69 days. $70 \%$ of the observations have less than 30 days of training per year. Notably, about $19 \%$ of individuals who participated in training followed educational programs with a duration of at least 260 days (1 year in our definition). An example for such a long-term educational program could be a part-time training program to become a yoga teacher. In Sect. 4.2, we also look at different types of training.

\subsection{Job change incidence}

Since there is no direct information about job changes in the survey, we construct a dummy variable for job change $J_{i t}$, which indicates whether individual $i$ starts a new

\footnotetext{
16 Days of training is calculated using the survey question "What is the official duration of this program or course? _ (part-days/days/weeks/months/years)." On average, the days of the first, second and third training are 58, 21 and 15 days. For the total days of training, we add up the days of the three training programs. The maximum possible total days of training per year is $3 \times 260=780$ days.
} 
Table 4 Descriptive statistics

\begin{tabular}{lll}
\hline Variables & Mean & SD \\
\hline Dependent variable & & \\
Job match quality & 0.711 & 0.149 \\
Job change incidence & 0.061 & 0.240 \\
Treatment & & \\
Training & 0.368 & 0.482 \\
Total days of training per year (conditional on participating in training) & 68.880 & 116.137 \\
Single training & 0.215 & 0.411 \\
Multiple training & 0.151 & 0.358 \\
Demographics & & \\
Female & 0.515 & 0.500 \\
Age in years & 44.257 & 11.309 \\
Disabled & 0.011 & 0.103 \\
Individuals & 4905 & \\
Observations & 21,992 & \\
\hline
\end{tabular}

job in year $t$, inferred from "the year when entering the current job." $J_{i t}$ equals 1 if "the year when entering the current job" changes compared to the last period.

Table 4 presents the main descriptive statistics of our estimation sample. The sample size is 21,992 observations. About $52 \%$ of our sample are women. The average age is 44 years. Training is quite common in the Netherlands, with an incidence rate of $36.8 \%$ per year. On average, about $6.1 \%$ of all workers change jobs in a given year.

Figure 2 shows the average match quality over years relative to the year in which an individual receives training. If an individual received training in multiple years, each episode of training is considered separately. The plot on the left defines years between two trainings as "years after training." For example, if we denote receiving training in a year as " 1 " and no training as " 0 " and an individual's training sequence from year 2008 to 2015 is: " $0,1,0,0,1,1,0,0$," then for this sequence the year relative to training is " $t-1, t, t+1, t+2, t, t, t+1, t+2$." We compute average match quality for all observations at each year relative to training, for example at " $t+1$, , " $t+2$," and so on. The plot on the right defines years between trainings as "years before training." Then, for the example above the training sequence " $0,1,0,0,1,1,0,0$ " corresponds to " $t-1, t, t-2, t-1, t, t, t+1, t+2$."

The two plots in Fig. 2 show the same pattern. There is no dip in job match quality immediately before training. Job match quality is flat in the years before and after training, with an increase in the year of training only, suggesting that training only has a short-run effect on job match quality. This small and instantaneous increase in match quality does not necessarily reflect the causal impact of training, as we will further discuss in the next section. 

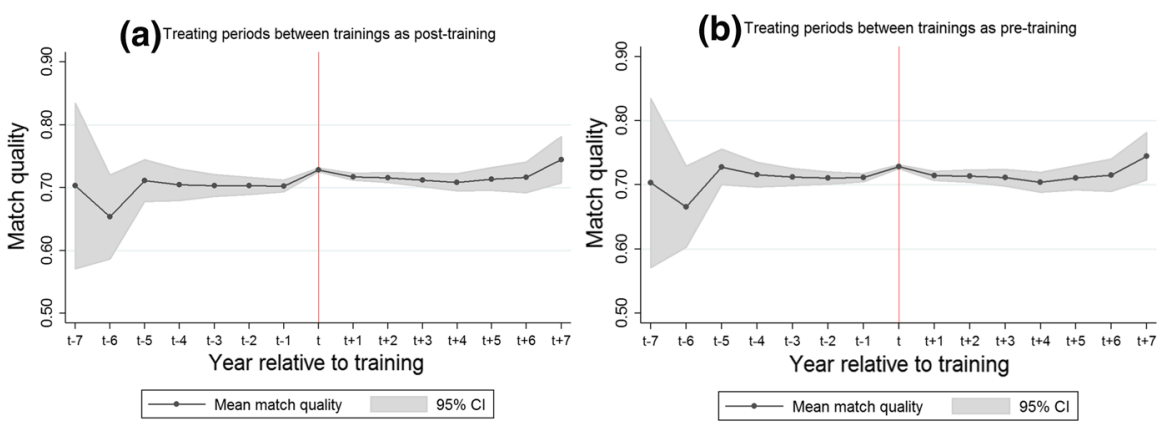

Fig. 2 Match quality over years relative to training

\section{The effect of training on job match quality}

The primary interest of this paper is to understand the causal effect of training on job match quality. As already discussed in Sect. 1, training may be endogenous. A first potential source of endogeneity is the presence of unobserved individual characteristics that simultaneously drive participation in training and perceived job match quality. Another potential source of endogeneity can be unobserved employer policy if, for example, some firms deliberately hire employees that first need to be trained before they are ready for the job. Moreover, there might be reverse causality between training and match quality-individuals who experience an unexpected change in the quality of their match may change their participation in training in the same year.

In order to address the above issues, we specify the following dynamic linear panel data model:

$$
M_{i t}=\sum_{j=1}^{3} \theta_{j} M_{i t-j}+\gamma T_{i t}+X_{i t}^{\prime} \beta+\alpha_{i}+\varepsilon_{i t}
$$

For $t=4$ to 8 and $i=1 \ldots \mathrm{N} .^{17}$

$M_{i t}$ is the constructed index of job match quality. The $M_{i t-j}$ are lagged dependent variables, with "state dependence" coefficients $\theta_{j} .{ }^{18}$ They capture dynamics in $M_{i t}$, e.g., due to partial adjustment. For example, a worker with low perceived job match quality last year (low $M_{i t-1}$ ) who did not change jobs, is likely to still have low perceived quality this year (low $M_{i t}$ ).

$T_{i t}$ is a dummy variable for training. Note that $T_{i t}$ measures the training participation in the time interval between $t-1$ and $t$ (the past 12 months), while $M_{i t}$ is the job match quality measured at time $t .{ }^{19}$ The parameter $\gamma$ is the short-run treatment effect of training on job match quality. Effects in the longer run also depend on the $\theta_{j}$. A more general local average treatment effect (LATE) interpretation of $\gamma$ does not seem

\footnotetext{
17 Observations in years 2008-2011 are dropped due to the inclusion of lagged dependent variables.

18 Our choice of using three lags is based upon specification tests; specifications with one or two lags are rejected by the Arellano-Bond serial correlation test.

19 In an alternative specification, we added lagged training $T_{i t-1}$, but this was not significant.
} 
possible, since there is no good reason why the monotonicity condition should be satisfied. $^{20}$

$X_{i t}$ is a vector of control variables, including age, age squared, and dummy variables for work disability and calendar years. Since they cannot be chosen by the worker, it seems plausible to assume that they are strictly exogenous (i.e., independent of all $\left.\varepsilon_{i s}, s=1, \ldots, T\right)$. We do not control for current education or job characteristics because they may change as the result of training. Past education and job characteristics are captured in $M_{i t-j}$.

The $\alpha_{i}$ refer to individual fixed effects, capturing time-invariant unobserved heterogeneity such as genetic traits and personality. The $\varepsilon_{i t}$ are idiosyncratic error terms, assumed to be independently and identically distributed. We assume that $\varepsilon_{i t}$ is an "innovation," independent of everything that happened before time period $t$, including $T_{i 1}, \ldots, T_{i t-1}$. This seems plausible, since individuals cannot make training decisions that anticipate unpredictable future shocks in job match quality. On the other hand, this assumption allows for an arbitrary correlation between $\varepsilon_{i t}$ and training in current and future periods. In other words, past or current shocks to match quality may influence training participation in the same time period or in later time periods. In this way, we exploit the timing of events for identification. The identifying assumptions are supported by the usual tests for misspecification: both the Sargan test based upon over-identifying restrictions and the Arellano-Bond test for autocorrelation in the error terms lead to the conclusion that the assumption cannot be rejected.

The dynamic panel data model introduced above is estimated with system GMM estimation (Blundell and Bond 1998) with finite sample correction for the variance of linear efficient two-step GMM estimators (Windmeijer 2005). ${ }^{21}$ The instruments for the differenced equation are $M_{i t-2}$ to $M_{i t-7}$, and $\Delta X_{i t}$ for $t=5$ to 8 . Since the error term in the differenced equation is $\varepsilon_{i t}-\varepsilon_{i t-1}$, these instruments are valid if $\varepsilon_{i t}$ is indeed independent of everything before time period $t$. The instruments for the level equation are $\Delta T_{i t-1}$ and $\Delta M_{i t-1}$ for $t=4-8$. Their use relies on auxiliary stationarity assumptions, see Blundell and Bond (1998). Table A.4 in online Appendix shows how sensitive the estimated coefficient of training $\widehat{\gamma}$ is when we vary the instruments of training and lagged dependent variables. For all the GMM estimation results, we report the $p$ values of the Sargan test and the Arellano-Bond autocorrelation test for the validity of the model assumptions. In all cases presented, the $p$ values imply that the model assumptions are not rejected using tests of size $\alpha=0.05$.

In order to see how ignoring the dynamics of job match quality and the endogeneity of training could bias the estimates, we first present some alternative estimates, requiring a variety of different assumptions in order to interpret the estimate of $\gamma$ as causal (Columns 1-5 in Table 5). The first two columns are static models that assume there is no state dependence in job match quality. According to the OLS estimates (Table 5, Column 1), training increases perceived job match quality by 0.032 , i.e., $21 \%$ of one standard deviation of the index. This shows that training and job match quality are positively associated, but it would give an estimate of the causal effect of

\footnotetext{
20 (The change in) Past training is used as an instrument for (the change in) current training. The effect of past training on current training may be positive in some cases (habit formation, advantages of continuous learning) but negative in others (firms may stimulate different workers for training each year).

21 Arellano-Bond GMM estimates (Arellano and Bond 1991) give similar results.
} 


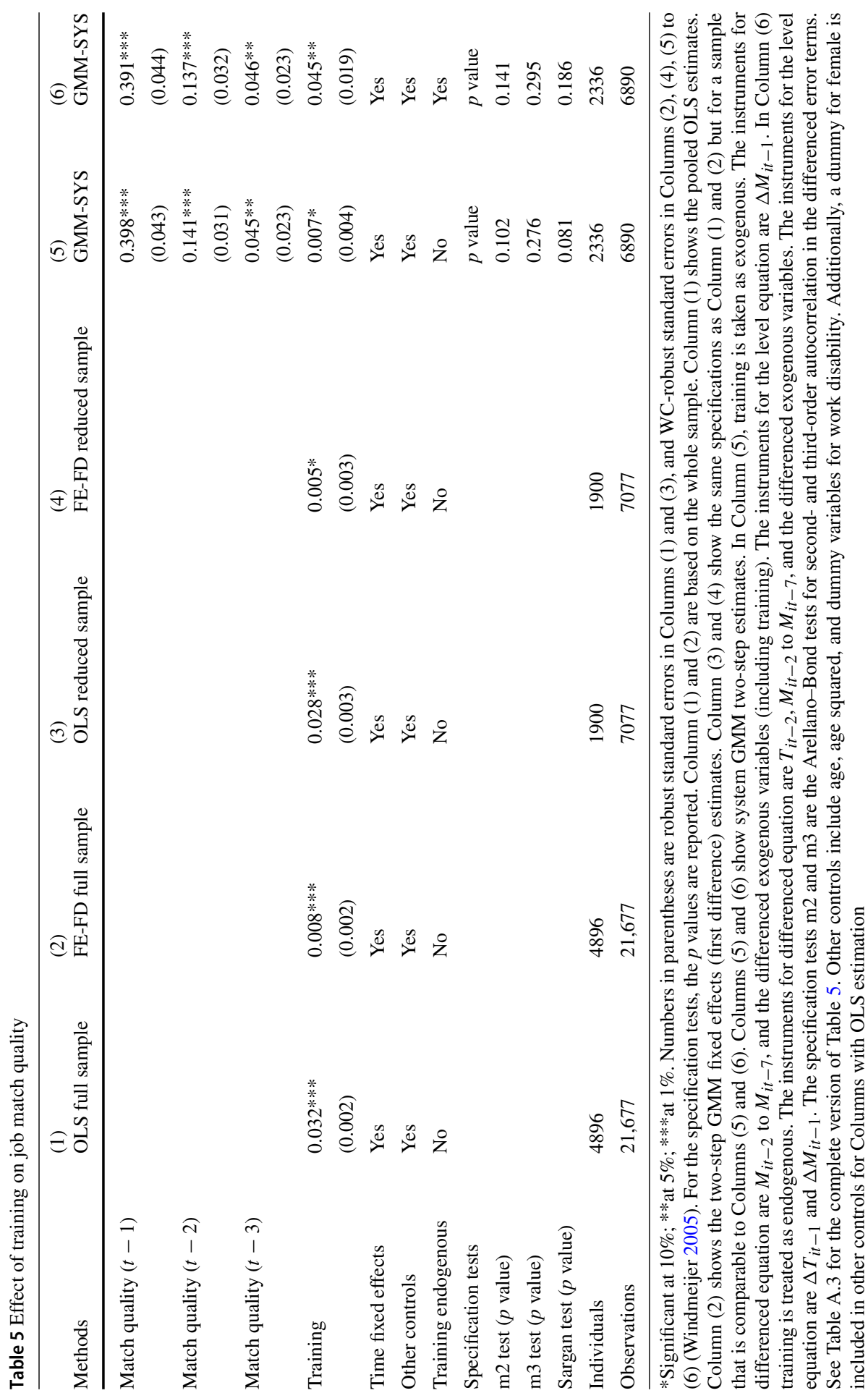


training only if training and the control variables are uncorrelated with $\alpha_{i}+\varepsilon_{i t}$, which does not seem plausible.

When we take account of individual unobserved heterogeneity and move to static linear fixed effects panel data models [Column 2 with first-difference fixed effects estimates (FE-FD)], the magnitude of the estimates reduce from 0.032 to 0.008 . This is a consistent estimate of the causal effect only if training is uncorrelated with $\varepsilon_{i t}$ ("contemporaneous exogeneity" of training), excluding an immediate effect of job match quality on the decision to participate in training. The difference between the estimates of $\gamma$ in Columns 2 and 1 suggests a positive relation between training and the individual fixed effect, implying that more ambitious or capable people have more opportunities to take training and also higher perceived match quality.

To allow for differences in short-term and long-term effects, we move to dynamic models in Columns 5 and 6 that account for state dependence in job match quality. The main difference between Columns 5 and 6 is the assumption on training. Column 5 presents system GMM estimates, but the moments used assume that training is contemporaneously exogenous. The estimated effect of training in this specification is 0.007 .

We cannot directly compare this number 0.007 with 0.008 in Column 2 because the inclusion of lagged dependent variables results in a smaller sample. We therefore construct a comparable sample keeping individuals observed for at least 2 consecutive years for first-differencing and dropping observations from year 2008 to 2011 for the lagged dependent variables. ${ }^{22}$ Based on this reduced sample, we run the same estimation as in Columns 1 and 2, which yields the results in Columns 3 and 4 , respectively. The estimates for $\gamma$ are slightly smaller than for the full sample (cf. Column 1). Column 4 shows that the estimate of $\gamma$ in a static fixed effects model on the smaller sample is only 0.005 (standard error 0.003), which is smaller than the 0.007 estimate (standard error 0.004) in Column 5. This suggests that omitting lagged dependent variables tends to bias the effect of training downwards.

Column 6 presents the estimates based on the assumptions, instruments, and moments discussed in the previous section, allowing training to be endogenous and instrumenting training with past training. This is our preferred specification. The estimated effect of training increases to 0.045 . A possible explanation for the large change compared to Column 5 could be that workers who suffer from a poor current job match are inclined to take training in the same year to improve job match quality. This would make training contemporaneously endogenous. Ignoring this endogeneity ("reverse causality") will lead to underestimation of the effect of training. ${ }^{23}$

The significant lag terms show that there is positive state dependence in the dynamic adjustment process of job match quality. The short-term effect of training on job match quality is 0.045 . The long-run effect is $\frac{\gamma}{1-\left(\theta_{1}+\theta_{2}+\theta_{3}\right)}=\frac{0.045}{1-(0.391+0.137+0.046)}=0.106$,

\footnotetext{
22 The sample size for the comparable sample is not exactly the same as in Columns 5 and 6 . This is due to differences in reporting sample sizes across STATA commands. For example, individuals with only 1 year of observation, which do not contribute to the first-differencing estimation results, are not automatically dropped from the sample. In spite of the slight difference, we show in Table A.9 that the descriptive statistics for the reduced sample are similar to those in Table 4.

23 A Hausman specification test on the training coefficient shows that the specification estimated in Column 5 is rejected against the more general specification in Column 6 ( $p$ value 0.041).
} 
more than twice as large. This means that if an individual permanently changes from no training to training in each year (e.g., life-long learning), perceived job match quality improves by approximately $70 \%$ of one standard deviation of the index in the long-run.

The only control variable of substantive interest is the dummy variable "disabled" (see Table A.3). Keeping other variables constant, having a disability significantly reduces the perceived match.

\section{Mechanisms}

As discussed in Sect. 1, there are different types of training, and these may have different effects on job match quality. To understand why we found substantial positive overall effects of training on job match quality, we distinguish different types of training according to the purpose for which the training is taken. We consider training to improve human capital (Becker 1962), training taken to improve labor market opportunities (the "career mobility theory" of Sicherman and Galor 1990), and training taken for other purposes. We also investigate whether the types of training work through their intended mechanism.

We use the following survey question asked to all workers who took some training: "What was your main reason to start following this program or course?" The answers "1 to stay up-to-date in my profession (3773 observations)" and "2 to gain promotion (493 obs.)" are categorized as "training for human capital build-up." The answer "3 to increase my chances of getting another job (657 obs.)" is categorized as "training for job change." The remaining reasons are categorized as "other training." 24 The majority participates in training for human capital build-up purpose (4266 out of 8044). Around $8 \%$ of all training is taken for the purpose of changing jobs. ${ }^{25}$

To estimate separate effects of training for the three purposes, we replaced the training variable with three indicators for the three types of training and estimated a model similar to the main estimation (Table 5, Column 6), allowing for the endogeneity of training and its purpose. We make essentially the same identifying assumptions as before (Table 5, Column 6) - shocks in job match quality are not related to past training (or purpose of training) or past job match quality. The results are summarized in Table 6, Column $1 .{ }^{26}$

We find that training for human capital improvement has a large and significant effect, improving job match quality in the short-run by 0.079 (53\% of a standard

\footnotetext{
24 The remaining answers are "4 required by my job (2219 obs.)," "5 required by CWI/UWV/Public Employment Service (15 obs.)," "6 required by municipality or social service (15 obs.)," "7 am still of school age (34 obs.)," "8 am still completing my school career (147 obs.)," and "9 for another reason (691 obs.)". In an alternative estimation, we drop the 211 observations in answer 5, 6, 7, and 8. This makes hardly any difference for the results.

25 If a respondent took several training programs in a given year, this classification is based on the first reported training. This assumes that the first training is the most important training, which is supported by the fact that the average duration of the first training per year is 58 days, compared to 21 days for the second and 15 days for the third training. In Table A.5, we present the results of a sensitivity check with a non-mutually exclusive way of defining type of training, treating different training programs equally. In this
} 
Table 6 Effect of training by purpose and effect of training through job change

\begin{tabular}{|c|c|c|c|}
\hline $\begin{array}{l}\text { GMM-SYS } \\
\text { Dependent variable }\end{array}$ & $\begin{array}{l}\text { (1) } \\
\text { Match quality }\end{array}$ & $\begin{array}{l}(2) \\
\text { Job Change Incidence }\end{array}$ & $\begin{array}{l}\text { (3) } \\
\text { Job Change Outcome }\end{array}$ \\
\hline Match quality $(t-1)$ & $\begin{array}{l}0.367 * * * \\
(0.087)\end{array}$ & $\begin{array}{l}-0.225^{* * *} \\
(0.056)\end{array}$ & $\begin{array}{l}-0.334^{* * *} \\
(0.105)\end{array}$ \\
\hline Match quality $(t-2)$ & $\begin{array}{l}0.127 * * * \\
(0.048)\end{array}$ & & \\
\hline Match quality $(t-3)$ & $\begin{array}{l}0.044 * \\
(0.023)\end{array}$ & & \\
\hline Human capital build-up training & $\begin{array}{l}0.079 * * * \\
(0.025)\end{array}$ & $\begin{array}{l}-0.049 \\
(0.051)\end{array}$ & $\begin{array}{l}0.080 \\
(0.069)\end{array}$ \\
\hline Human capital build-up training $(t-1)$ & & & $\begin{array}{l}-0.006 \\
(0.014)\end{array}$ \\
\hline Job change training & $\begin{array}{l}0.019 \\
(0.050)\end{array}$ & $\begin{array}{l}0.237^{*} \\
(0.122)\end{array}$ & $\begin{array}{l}-0.057 \\
(0.105)\end{array}$ \\
\hline Job change training $(t-1)$ & & & $\begin{array}{l}0.060 * * \\
(0.029)\end{array}$ \\
\hline Other training & $\begin{array}{l}0.014 \\
(0.030)\end{array}$ & $\begin{array}{l}0.124 * * \\
(0.052)\end{array}$ & $\begin{array}{l}0.081 \\
(0.058)\end{array}$ \\
\hline Other training $(t-1)$ & & & $\begin{array}{l}-0.007 \\
(0.014)\end{array}$ \\
\hline Time fixed effects & Yes & Yes & Yes \\
\hline Other controls & Yes & Yes & Yes \\
\hline Training endogenous training & Yes & Yes & Yes \\
\hline Specification tests & $p$ value & $p$ value & $p$ value \\
\hline $\mathrm{m} 2$ test & 0.137 & 0.332 & 0.677 \\
\hline $\mathrm{m} 3$ test & 0.243 & 0.554 & 0.661 \\
\hline Sargan test & 0.592 & 0.201 & 0.154 \\
\hline Individuals & 2336 & 4867 & 4823 \\
\hline Observations & 6890 & 15,666 & 15,495 \\
\hline
\end{tabular}

*Significant at $10 \%$;**at 5\%; ***at $1 \%$. Numbers in parentheses are WC-robust standard errors. For the specification tests, the $\mathrm{p}$ values are reported. All columns are estimated with system GMM estimator. In Columns (1) and (2), the instruments are similar to those in Column (6) of Table 5, except that all the instruments of training are replaced with instruments of three types of training: "human capital build-up training," "job change training," and "other training." In Column (3), $T_{i j t-2}$ to $T_{i j t-7}$ and $M_{i t-2}$ to $M_{i t-7}$ are used as instruments for differenced equation. In all columns, we use differenced exogenous variable as instruments for differenced equation. And we use $\Delta T_{i j t-1}$ and $\Delta M_{i t-1}$ for the level equation. The specification tests $\mathrm{m} 2$ and $\mathrm{m} 3$ are the Arellano-Bond tests for second- and third-order autocorrelation in the differenced error terms. Other controls are the same as those in Table 5. In Column (3), we drop 315 observations with missing values for job match quality 
deviation) and in the long-run by $0.171 .^{27}$ Since this is also the most common purpose of training, this finding implies that training for human capital improvement largely explains the positive training effects we found in Sect. 3. The effect of training for job change is not significantly different from zero, but also not significantly different from the effect of training for human capital improvement. The effect of other training (mainly training "required by my job") is even smaller and also insignificant.

In the other columns of Table 6, we analyze whether training for a given purpose indeed affects job match quality through the intended mechanism, with a focus on changing jobs or not. We use the same type of dynamic panel data model as in our main estimation, accounting for the dynamics of job match quality, for fixed individual effects, and for endogeneity of the training variables (cf. the model in Column 6 of Table 5). We do not include the second and third lags of job match quality because they are jointly insignificant.

Column 2 considers the intermediate step: it explains the likelihood of a job change, one possible pathway to improve job match quality. It shows that training for job change purposes tends to achieve its goal: it substantially increases the probability to switch jobs. The effect of other training on job change incidence is also positive and significant. But the training for human capital improvement has no such effects. This is in line with Cheng and Waldenberger (2013) who find that the effect of training on job change depends on the type of training, though their distinction between training types is different: they find that training for specific skills is associated with lower turnover intentions, while training for general skills is associated with higher turnover intentions. Column 2 also shows that a higher past job match quality significantly lowers the probability to change jobs.

The final column in Table 6 analyzes whether training helps to find not only a new job but also a better match. ${ }^{28}$ This question is related to the topic of Dekker et al. (2002), who study how training influences upward mobility (job-to-job moves that result in an increase in job level) and lateral mobility (moves without change of job level). They use cross-sectional data and include training participation as an exogenous variable, controlling for many other individual and job characteristics

Our dynamic linear panel data model is similar to the earlier models (e.g., Column 6 in Table 5) and accounts for potential endogeneity in training in the same way. Moreover, based upon the preliminary estimation results, we added past training participation as explanatory variables. The dependent variable is a constructed variable "job change outcome" $O_{i t}$ interacting the job change incidence dummy with the sign of the change of job match quality ( -1 for a deterioration, 0 for no change, 1 for an improvement). It equals 0 when individual $i$ does not change jobs in year $t$, or changes

\footnotetext{
Footnote 25 continued

case, for an individual who participates both in job change training and other training, both type-of-training variables will take value 1 . The results retain the same pattern.

26 We also tried adding lags of the training variables but their coefficients were very small and jointly insignificant.

27 Calculated as 0.079/(1-0.367-0.127-0.044).

28 Previous studies on how job changes influence mismatch (Congregado et al. 2016) or job satisfaction (Zhou et al. 2017) give the mixed results. Congregado et al. find hardly any effect, while Zhou et al. (2017) find a positive short-run effect on job satisfaction. These studies did not address the role of training.
} 
to a job but retains the same level of job match quality. It is -1 when the worker changes to a new job with lower job match quality and 1 when the worker changes to a job with higher match quality. ${ }^{29}$ We therefore do not condition on job changes, but explain the joint outcome of whether someone changes jobs or not and if so, how this changes job match quality.

Most of the time, no job change takes place (20,357 observations). Of the 1320 observed job changes, $61.4 \%$ are changes to a better match (810 observations with $\left.O_{i t}=1\right)$ and $36.4 \%$ to a worse match (480 observations with $O_{i t}=-1$ ), while the remaining $2.2 \%$ change to a new job with the same perceived match quality (30 observations).

The estimated coefficient of training in this model can be interpreted as the effect of training on the difference between the probabilities of changing to a job with better quality and changing to a job with worse quality. ${ }^{30}$ As expected, the estimated coefficient of the lagged job match quality is negative, because the higher the match quality in the old job, the less likely is a change to a job with even higher match quality.

The immediate effect of job change training is not significant, but job change training does have a significant positive effect on the job change outcome 1 year later. The estimated coefficient means that participating in job change training in the last period will increase the probability difference by 0.060 , raising the probability of getting a new job with a better match, and/or reducing the probability of getting a worse-matched new job. This finding is in line with career mobility theory. Training for other purposes than changing jobs (training for human capital improvement or other purposes) has no significant effect, as expected. ${ }^{31}$

Combining the results in Columns 2 and 3 suggests that taking job change training will increase the probability to change jobs immediately, but there is no evidence that these immediate changes tend to lead to better job matches. For those who take some time and change jobs in the next period, job change training tends to lead to a better-matched job.

\section{Sensitivity analysis}

One concern might be the unbalanced panel structure caused by sample attrition. To investigate if our results are influenced by sample attrition, we further restrict the sample to observations that are in the data for at least five consecutive years. The resulting sample is more balanced but also more selective (see Table A.8 in online Appendix). ${ }^{32}$ We reconstructed (and rescaled) the dependent variable for this new sample and performed the same system GMM estimation; see Column 1 of Table 7. The estimated effect of training is slightly smaller than the original estimate, possibly because the new sample leaves out individuals with more unstable employment status

\footnotetext{
29 Here, we drop 315 observations with missing values for job match quality.

30 Because in linear model, $E\left(O_{i t}\right)=1 \cdot P\left(O_{i t}=1\right)+0 \cdot P\left(O_{i t}=0\right)-1 \cdot P\left(O_{i t}=-1\right)=P\left(O_{i t}=1\right)-P$ $\left(O_{i t}=-1\right)$. Separate estimates for the effects on improvement and deterioration through job change give less precise and insignificant results.

31 The coefficients of the four training dummy variables are jointly insignificant.

32 The new sample has fewer workers engaged in temporary jobs, unskilled jobs, and self-employment.
} 
Table 7 Sensitivity analysis

\begin{tabular}{|c|c|c|c|c|c|}
\hline \multirow{2}{*}{$\begin{array}{l}\text { GMM-SYS } \\
\text { Dependent } \\
\text { variable } \\
\begin{array}{l}\text { Match quality } \\
(t-1)\end{array}\end{array}$} & \multirow{2}{*}{$\begin{array}{l}\text { (1) } \\
\text { Match quality (5 } \\
\text { consecutive yrs) }\end{array}$} & \multirow{2}{*}{$\begin{array}{l}\text { (2) } \\
\text { Match quality } \\
\text { (Truncated) }\end{array}$} & \multirow{2}{*}{$\begin{array}{l}\text { (3) } \\
\text { Match quality (8 } \\
\text { components) }\end{array}$} & \multicolumn{2}{|c|}{$\begin{array}{l}(4) \quad(5) \\
\text { Match quality } \\
\text { (Alternative treatment }\end{array}$} \\
\hline & & & & $0.396 * * *$ & $0.381 * * *$ \\
\hline & $(0.044)$ & $(0.074)$ & $(0.047)$ & $(0.081)$ & $(0.099)$ \\
\hline \multirow{2}{*}{$\begin{array}{l}\text { Match quality } \\
\quad(t-2)\end{array}$} & $0.130 * * *$ & $0.120 * *$ & $0.155 * * *$ & $0.142 * * *$ & $0.133 * *$ \\
\hline & $(0.031)$ & $(0.050)$ & $(0.036)$ & $(0.046)$ & $(0.060)$ \\
\hline \multirow{2}{*}{$\begin{array}{l}\text { Match quality } \\
\quad(t-3)\end{array}$} & $0.041^{*}$ & 0.027 & $0.060 * *$ & $0.046^{*}$ & $0.045^{*}$ \\
\hline & $(0.022)$ & $(0.027)$ & $(0.025)$ & $(0.024)$ & $(0.024)$ \\
\hline \multirow[t]{2}{*}{ Training } & $0.037^{*}$ & $0.034 *$ & $0.039 * *$ & & \\
\hline & $(0.021)$ & (0.019) & $(0.018)$ & & \\
\hline \multirow{2}{*}{$\begin{array}{l}\text { Days of } \\
\text { training }\end{array}$} & & & & $0.0002 * *$ & \\
\hline & & & & $(0.0001)$ & \\
\hline \multirow[t]{2}{*}{ Single training } & & & & & 0.047 \\
\hline & & & & & $(0.035)$ \\
\hline \multirow{2}{*}{$\begin{array}{l}\text { Multiple } \\
\text { training }\end{array}$} & & & & & 0.035 \\
\hline & & & & & $(0.032)$ \\
\hline $\begin{array}{l}\text { Time fixed } \\
\text { effects }\end{array}$ & Yes & Yes & Yes & Yes & Yes \\
\hline Other controls & Yes & Yes & Yes & Yes & Yes \\
\hline $\begin{array}{l}\text { Training } \\
\text { endogenous }\end{array}$ & Yes & Yes & Yes & Yes & Yes \\
\hline $\begin{array}{l}\text { Specification } \\
\text { tests }\end{array}$ & $p$ value & $p$ value & $p$ value & $p$ value & $p$ value \\
\hline $\mathrm{m} 2$ test & 0.131 & 0.294 & 0.277 & 0.126 & 0.198 \\
\hline $\mathrm{m} 3$ test & 0.270 & 0.162 & 0.272 & 0.228 & 0.311 \\
\hline Sargan test & 0.120 & 0.175 & 0.418 & 0.179 & 0.393 \\
\hline Individuals & 1600 & 2188 & 2061 & 2336 & 2336 \\
\hline Observations & 6154 & 6326 & 5901 & 6890 & 6890 \\
\hline
\end{tabular}

*Significant at 10\%; **at 5\%; ***at $1 \%$. Numbers in parentheses are WC-robust standard errors. $p$ value for the specification tests. All the model specifications and instrument choices are the same as those in the main estimation; see notes in Table 5

who may potentially benefit more from training. The same reasoning suggests that, due to attrition, the estimated effect of training according to our preferred estimates in Table 5, Column 6 also slightly underestimates the effect in the complete population.

Another concern is the skewed distribution of the dependent variable. In response to this concern, we truncate the distribution of job match quality at $0.42116 .{ }^{33} \mathrm{We}$

33 This is calculated as mean- $(\max -$ mean $)$ of the dependent variable: $0.71058-(1-0.71058)=0.42116$. 
do the same estimation with the truncated sample. Column 2 of Table 7 shows that the effect of training remains positive and significant, though it is slightly reduced in magnitude. This makes sense since truncation removes the most mismatched workers, who may benefit most from training.

Third, we check if the results are sensitive to which components we include to construct our measure of job match quality. Besides the five variables used in the main body of the paper, we further include "satisfaction with earnings," "satisfaction with working hours," and "satisfaction with the general atmosphere among your colleagues." These three variables focus on satisfaction with specific job characteristics, rather than the overall perception of the quality of the match and seem less directly affected by training. Table B.1 in the Online Appendix displays their summary statistics, showing that average satisfaction with wages or earnings is lower than other satisfaction averages. Table B.2 shows that they are positively correlated among each other and with the other five variables used to construct the index, but the correlations tend to be somewhat weaker than those among the five original variables. Table B.3 presents the new factor loadings, showing that the three new variables give positive but lower weights, indicating that they are conceptually farther away from the underlying perceived job match quality. Figure B.1 shows that the new measure constructed with extra components has a similar distribution as in Fig. 1. The main estimation results using the new job match quality index are in Column 3 of Table 7. The short-term effect of training is slightly smaller than in Table 5, but remains significant.

Next, we check which of the five components that we use to construct job match quality are driving the results. Table A.10 shows the results of the same model as in the last column of Table 5, separately for each of the five variables that are included in our composite measure of job match quality. Note that the variables are scaled differently, so all the estimated coefficients are about ten times larger. Training has a large and significant effect on satisfaction metrics, especially for satisfaction with current work and satisfaction with career, but training has also a large and significant effect on educational match. This could be related to the fact that quite a few training programs are formal education (e.g., 1-year part-time vocational education program).

The fifth robustness check is to use alternative treatment variables. In Column 4 of Table 7, the variable "days of training" is constructed as the total days of all training programs that a worker received in the last 12 months. We assume the effect of training is linear in days and additive across multiple programs. The estimated coefficient shows that one day of training significantly increases the job match quality by 0.0002 . On average, workers taking training take about 69 days, giving a much smaller effect $(0.0002 \times 69 \approx 0.014)$ than the main estimate of 0.045 in Table 5. In additional analysis (not presented), we find that training programs lasting no longer than seven days (the majority of cases) are the most effective ones, indicating that the effect of training might be concave in the duration of the training.

In Column 5, we construct two mutually exclusive dummy variables "receiving a single training program" and "receiving multiple training programs." The estimated coefficients on these two variables are not significantly different from each other, which indicates that it is the participation in training or not that really matters and not the number of training programs taken. 
The final robustness checks use alternative definitions of type of training, job change outcomes, and job match quality. In Table A.5, we utilize information on multiple training programs to construct a non-mutually exclusive classification of training: for an individual who participates in job change training as well as other training, both types of training variable will take the value 1 . In Table A.6, job change outcome $\left(O_{i t}\right)$ is a continuous variable defined as the interaction of the job change incidence $J_{i t}$ with the improvement in job match quality $\Delta M_{i t}$ (instead of its sign). In Table A.7, we take the simple average of the five job match-related variables to construct an alternative index "new job match quality" instead of the index using factor analysis. 34 In all cases, the results and patterns are quite similar to those in the main analysis.

\section{Conclusion}

In recent years, researchers and policymakers have increasingly become aware of the importance of job match quality. Previous studies find a positive relation between training and job match quality. We add to the literature by estimating the causal effect of training on job match quality using a different identification strategy, exploiting the timing of events in a dynamic panel data framework. We find that training has a positive short-run effect of approximately 0.045 (30\% of a standard deviation of the job match quality index) and a long-run effect of 0.106 (71\% of a standard deviation). This result is mainly driven by training programs aimed at building up additional human capital. To investigate the role of job changes in explaining the effect of training on job match quality, we explicitly incorporate job changes in the model and find that training for job change purposes immediately increases the probability of changing a job, while training for other purposes has no such positive effect. These immediate job changes are equally likely to end up in a worse-matched new job and in a better-matched new job. For those who change jobs 1 year later, however, training for job change purposes tends to lead to a job with a better match quality.

Our findings confirm that training helps to improve job match quality. This opens possibilities for policymakers who aim at improving job match quality to design policies with respect to training. Well-designed policies that encourage training could be instrumental to reach the European Union's strategic goal to "improve job match quality." Our findings suggest that training programs aimed at investing in workers' human capital are the most efficient way.

Acknowledgements The authors would like to thank CentERdata of Tilburg University for providing the data. We are very grateful for many helpful comments of the anonymous referee, the associate editor, and the coordinating editor. We are grateful to Jeffrey Campbell, Tobias Klein, Jan van Ours, Loes Verstegen, and seminar participants at Tilburg University and the 29th Annual Conference of EALE for their helpful comments and suggestions.

\footnotetext{
34 For the 315 observations who have one or several missing values in these five job match-related variables, we take the average of the available variables.
} 


\section{Compliance with ethical standards}

Conflict of interest Yi Zhang declares that she has no conflict of interest. Martin Salm declares that he has no conflict of interest. Arthur van Soest declares that he has no conflict of interest.

Ethical approval This article does not contain any studies with human participants or animals performed by any of the authors.

Open Access This article is licensed under a Creative Commons Attribution 4.0 International License, which permits use, sharing, adaptation, distribution and reproduction in any medium or format, as long as you give appropriate credit to the original author(s) and the source, provide a link to the Creative Commons licence, and indicate if changes were made. The images or other third party material in this article are included in the article's Creative Commons licence, unless indicated otherwise in a credit line to the material. If material is not included in the article's Creative Commons licence and your intended use is not permitted by statutory regulation or exceeds the permitted use, you will need to obtain permission directly from the copyright holder. To view a copy of this licence, visit http://creativecommons.org/licenses/by/4.0/.

\section{References}

Allen J, Van der Velden R (2001) Educational mismatches versus skill mismatches: effects on wages, job satisfaction, and on-the-job search. Oxf Econ Pap 53(3):434-452

Arellano M, Bond S (1991) Some tests of specification for panel data: Monte Carlo evidence and an application to employment equations. Rev Econ Stud 58(2):277-297

Barmby T, Bryson A, Eberth B (2012) Human capital, matching and job satisfaction. Econ Lett 117(3):548-551

Becker GS (1962) Investment in human capital: a theoretical analysis. J Polit Econ 70(5):9-49

Blundell R, Bond S (1998) Initial conditions and moment restrictions in dynamic panel data models. J Econom 87(1):115-143

Blundell R, Dias MC, Meghir C, Van Reenen J (2004) Evaluating the employment impact of a mandatory job search program. J Eur Econ Assoc 2(4):569-606

Burgard C, Görlitz K (2014) Continuous training, job satisfaction and gender: an empirical analysis using german panel data. In: Evidence-based HRM: a global forum for empirical scholarship, vol 2, no 2. Emerald Group Publishing Limited

Cheng Y, Waldenberger F (2013) Does training affect individuals' turnover intention? Evidence from China. J Chin Hum Resour Manag 4(1):16-38

Chiang C-F, Back K-J, Canter DD (2005) The impact of employee training on job satisfaction and intention to stay in the hotel industry. J Hum Resour Hosp Tour 4(2):99-118

Child D (2006) The essentials of factor analysis, 3rd edn. Continuum, London

Clark AE (2001) What really matters in a job? Hedonic measurement using quit data. Labour Econ $8(2): 223-242$

Clark AE (2005) Your money or your life: changing job quality in OECD countries. Br J Ind Relat 43(3):377-400

Clark AE (2015) What makes a good job? Job quality and job satisfaction. IZA World of Labor, Article 215 (2015)

Congregado E, Iglesias J, Millán JM, Román C (2016) Incidence, effects, dynamics and routes out of overqualification in Europe: a comprehensive analysis distinguishing by employment status. Appl Econ 48(5):411-445

Crépon B, Duflo E, Gurgand M, Rathelot R, Zamora P (2013) Do labor market policies have displacement effects? Evidence from a clustered randomized experiment. Q J Econ 128(2):531-580

Dekker R, De Grip A, Heijke H (2002) The effects of training and overeducation on career mobility in a segmented labour market. Int J Manpow 23(2):106-125

Dolton P, Vignoles A (2000) The incidence and effects of overeducation in the UK graduate labour market. Econ Educ Rev 19(2):179-198

Ferreira P, Taylor M (2011) Measuring match quality using subjective data. Econ Lett 113(3):304-306

Gaure S, Røed K, Westlie L (2012) Job search incentives and job match quality. Labour Econ 19(3):438-450 
Georgellis Y, Lange T (2007) Participation in continuous, on-the-job training and the impact on job satisfaction: longitudinal evidence from the German labour market. Int J Hum Resour Manag 18(6):969-985

Gottschalk P, Maloney T (1985) Involuntary terminations, unemployment, and job matching: a test of job search theory. J Labor Econ 3(2):109-123

Green F, Zhu Y (2010) Overqualification, job dissatisfaction, and increasing dispersion in the returns to graduate education. Oxf Econ Pap 62(4):740-763

Hair JF, Tatham RL, Anderson RE, Black WC (1998) Multivariate data analysis, 5th edn. Prentice-Hall International, London

Han K, Trinkoff AM, Storr CL, Lerner N, Johantgen M, Gartrell K (2014) Associations between state regulations, training length, perceived quality and job satisfaction among certified nursing assistants: cross-sectional secondary data analysis. Int J Nurs Stud 51(8):1135-1141

Harter JK, Schmidt FL, Hayes TL (2002) Business-unit-level relationship between employee satisfaction, employee engagement, and business outcomes: a meta-analysis. J Appl Psychol 87(2):268

Jones MK, Jones RJ, Latreille PL, Sloane PJ (2009) Training, job satisfaction, and workplace performance in Britain: evidence from WERS 2004. Labour 23(s1):139-175

Jovanovic B (1979) Job matching and the theory of turnover. J Polit Econ 87(5 Part 1):972-990

Kalleberg AL, Vaisey S (2005) Pathways to a good job: perceived work quality among the machinists in North America. Br J Ind Relat 43(3):431-454

Lachowska M, Meral M, Woodbury SA (2016) Effects of the unemployment insurance work test on longterm employment outcomes. Labour Econ 41(3):246-265

Le Barbanchon T (2016) "The effect of the duration of unemployment benefits on unemployment exits to work and match quality in France. Labour Econ 42(3):16-29

Mavromaras K, McGuinness S, O’Leary N, Sloane P, Wei Z (2013) Job mismatches and labour market outcomes: panel evidence on university graduates. Econ Rec 89(286):382-395

Messinis G, Olekalns N (2008) "Returns to training and skill mismatch: evidence from Australia." CSES Working Paper No. 40. Victoria University, Victoria

Mortensen DT (1978) Specific capital and labor turnover. Bell J Econ 9(2):572-586

Nordin M, Persson I, Rooth D-O (2010) Education-occupation mismatch: is there an income penalty? Econ Educ Rev 29(6):1047-1059

Pagán-Rodríguez R (2015) Disability, training and job satisfaction. Soc Indic Res 122(3):865-885

Pecoraro M (2014) Is there still a wage penalty for being overeducated but well-matched in skills? A panel data analysis of a Swiss graduate cohort. Labour 28(3):309-337

Sicherman N, Galor O (1990) A theory of career mobility. J Polit Econ 98(1):169-192

Stevens JP (1992) Applied multivariate statistics for the social sciences, 2nd edn. Erlbaum, Hillsdale

Topel RH, Ward MP (1992) Job mobility and the careers of young men. Q J Econ 107(2):439-479

Vahey SP (2000) The great Canadian training robbery: evidence on the returns to educational mismatch. Econ Educ Rev 19(2):219-227

Windmeijer F (2005) A finite sample correction for the variance of linear efficient two-step GMM estimators. J Econom 126(1):25-51

Zhou Y, Zou M, Williams M, Tabvuma V (2017) Is the grass greener on the other side? A longitudinal study of the impact of employer change and occupational change on job satisfaction. J Vocat Behav 99:66-78

Publisher's Note Springer Nature remains neutral with regard to jurisdictional claims in published maps and institutional affiliations. 